\title{
Synthesis of the pentasaccharide repeating unit of latosillan
}

\author{
Yuxia Hua, ${ }^{\mathrm{a}}$ Junjun Xiao, ${ }^{\mathrm{b}}$ Yingshen Huang ${ }^{\mathrm{b}}$ and Yuguo Du, ${ }^{\mathrm{a}, *}$ \\ ${ }^{a}$ State Key Laboratory of Environmental Chemistry and Ecotoxicology, Research Center for Eco-Environmental Sciences, \\ Chinese Academy of Sciences, Beijing 100085, China \\ ${ }^{\mathrm{b}}$ Department of Cell Biology, School of Basic Medical Sciences, Peking University, Beijing 100083, China
}

Received 25 October 2005; received in revised form 9 November 2005; accepted 14 November 2005

Available online 5 December 2005

\begin{abstract}
A pentasaccharide, $\beta$-D-Man- $(1 \rightarrow 2)-[\beta-D-G l c N A c-(1 \rightarrow 4)]-\alpha-L-R h a-(1 \rightarrow 4)-\alpha-L-R h a-(1 \rightarrow 4)-\alpha-L-R_{h}-1-O C_{8} H_{17}, \quad$ representing the repeating unit of latosillan, was convergently synthesized from the building blocks, ethyl 2,3-O-isopropylidene-1-thio$\alpha$-L-rhamnopyranoside, 2- $O$-acetyl-3,4,6-tri- $O$-benzyl- $\beta$-D-glucopyranosyl trichloroacetimidate, and 3,4,6-tri- $O$-acetyl-2-deoxy-2phthalimido- $\beta$-D-glucopyranosyl trichloroacetimidate under standard glycosylation conditions. The target pentasaccharide showed acceptable differentiation-inducing activity on HL-60 cell lines at the dosages of $10-50 \mu \mathrm{g} / \mathrm{mL}$.

(C) 2005 Elsevier Ltd. All rights reserved.
\end{abstract}

Keywords: Glycosylation; Latosillan; Cell differentiation; Oligosaccharides

\section{Introduction}

The mouse myeloid leukemia cell line M1 was originally established in vitro from a spontaneous leukemia SL strain in the mouse. ${ }^{1}$ It has been shown that M1 cells can be induced to differentiate into macrophages and granulocytes when treated with proteinous factors (Dfactors) in conditioned media from various cells and in various body fluids, and with chemicals such as gluco-

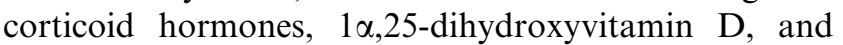
lipopolysaccharides. ${ }^{1-3}$ In the screening course for differentiation inducer of M1 cells, Ando and his co-workers ${ }^{4}$ have isolated a polysaccharide (named as latosillan later) from the culture filtrate of a bacterium, and a strong differentiation inducer activity was observed when incubated with M1 cells. The structure of latosillan was elucidated, from a degradation study and NMR spectral analysis, to be a heteroglycan composed of the repeating units of a pentasaccharide, $\left.{ }^{5} \rightarrow 2\right)-\beta$-D-Man- $(1 \rightarrow 2)$ - $[\beta$-DGlcNAc- $(1 \rightarrow 4)]-\alpha-L-R h a-(1 \rightarrow 4)-\alpha-L-R h a-(1 \rightarrow 4)-\alpha-L-$ Rha- $(1 \rightarrow$, as shown in Figure 1 .

To have a better understanding of this immunologically interesting observation and to compare the bioactivities between natural polysaccharide and the
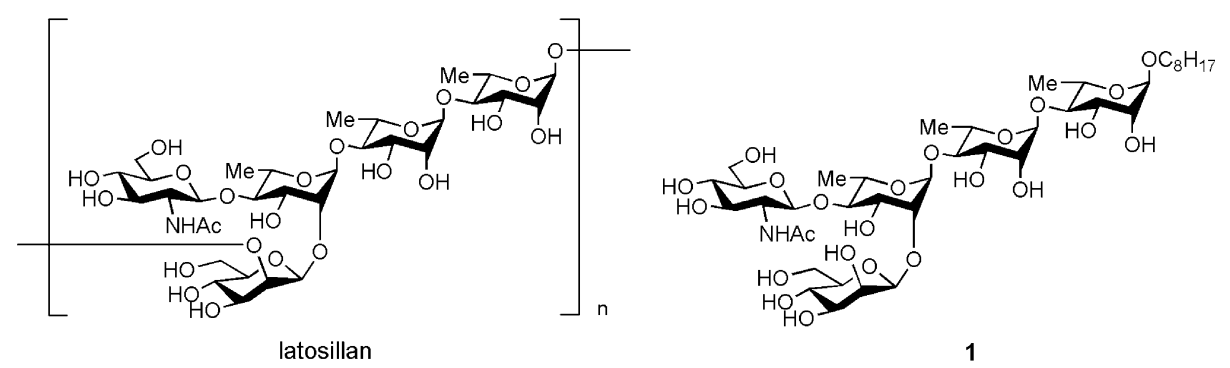

Figure 1. Structures of latosillan and compound $\mathbf{1 .}$

\footnotetext{
* Corresponding author. Tel.: +86 10 62914475; fax: +8610 62923563; e-mail: duyuguo@mail.rcees.ac.cn
} 
structural repeating unit, we launched a collaborative project regarding the preparation and potential medical application of latosillan-related analogues. Here, we would like to report the synthesis and preliminary biological studies of a latosillan pentasaccharide derivative.

\section{Results and discussion}

Pentasaccharide 1 was prepared via a convergent ' $3+2$ ' strategy. The synthesis of disaccharide acceptor 7 is described in Scheme 1. Ethyl 4- $O$-acetyl-2,3- $O$-isopropylidene-1-thio- $\alpha$-L-rhamonopyranoside $(3)^{6}$ was converted into its octyl glycoside 4 under standard NIS/TMSOTfcatalyzed glycosylation conditions. Zemplén deacetylation $^{7}$ of 4 with $\mathrm{NaOMe}$ in $\mathrm{MeOH}$ furnished octyl 2,3-O-isopropylidene- $\alpha$-L-rhamonopyranoside (5) in a yield of $86 \%$ for two steps. Glycosylation of $\mathbf{3}$ and 5 as described in the preparation of $\mathbf{4}$ gave octyl 4- $O$-acetyl2,3-O-isopropylidene- $\alpha$-L-rhamonopyranosyl-( $1 \rightarrow 4)-2,3-$ $O$-isopropylidene- $\alpha$-L-rhamonopyranoside (6), which was further deacetylated with $\mathrm{NaOMe}$ in $\mathrm{MeOH}$ furnishing disaccharide acceptor, octyl 2,3-O-isopropylidene$\alpha$-L-rhamonopyranosyl-( $1 \rightarrow 4)-2,3-O$-isopropylidene- $\alpha$-Lrhamnopyranoside (7) in $83 \%$ isolated yield for two steps. It is noteworthy that the chemical shift of $\mathrm{H}-1^{\mathrm{II}}$ appears at $\delta 5.60 \mathrm{ppm}\left(\mathrm{H}-1^{\mathrm{I}}\right.$ at $\left.\delta 4.95 \mathrm{ppm}\right)$ in the ${ }^{1} \mathrm{H}$ NMR spectrum of 7 , a significant difference compared to $\alpha-(1 \rightarrow 3)$ linked rhamnopyranosyl disaccharide (around $\delta 5.0 \mathrm{ppm}){ }^{8}$

In our initial synthesis of trisaccharide donor, we expected to establish a properly protected $\beta$-D-GlcNAc- $(1 \rightarrow 4)-\alpha-\mathrm{L}-\mathrm{R}$ ha residue first, then attach the $2-O$ acetyl-3,4,6-tri- $O$-benzyl- $\beta$-D-glucopyranosyl residue to the 2-OH of the above rhamnose unit, followed by O-deacetylation-oxidation-reduction on C-2 of the glucose unit to furnish a $\beta$-D-mannose containing trisaccharide. However, the multistep reactions finally gave an inseparable mixture having both $\beta$-D-GlcNAc- $(1 \rightarrow 4)$ $[\beta-\mathrm{D}-\mathrm{Man}-(1 \rightarrow 2)]-\alpha-\mathrm{L}-\mathrm{Rha}$ and $\beta$-D-GlcNAc- $(1 \rightarrow 4)-[\beta$ $\mathrm{D}-\mathrm{Glc}-(1 \rightarrow 2)]-\alpha-\mathrm{L}-\mathrm{R}$ ha in a ratio of about $4: 1$. We thus modified our strategy towards the synthesis of trisaccharide donor 18, as outlined in Scheme 2.

Treatment of rhamnopyranosyl thioglycoside $\mathbf{2}$ with butanedione, triethyl orthoformate, and $\mathrm{TsOH}$ in $\mathrm{EtOH}$ furnished compound $\mathbf{8}$ with its trans-OHs blocked in $79 \%$ yield. ${ }^{9}$ To prove this regioselectivity, 8 was acetylated with acetic anhydride in pyridine generating $\mathbf{9}$, which provided a chemical shift of $\mathrm{H}-2$ at $5.13 \mathrm{ppm}$ $(J=3.2,1.4 \mathrm{~Hz})$ in the ${ }^{1} \mathrm{H}$ NMR spectrum, confirming the structure of $\mathbf{8}$. Coupling of $\mathbf{8}$ and 2-O-acetyl-3,4,6tri- $O$-benzyl- $\beta$-D-glucopyranosyl trichloroacetimidate (10) ${ }^{10}$ in the presence of a catalytic amount of TMSOTf in $\mathrm{CH}_{2} \mathrm{Cl}_{2}$ at $0{ }^{\circ} \mathrm{C}$ gave ethyl 2- $O$-acetyl-3,4,6-tri- $O$-benzyl- $\beta$-D-glucopyranosyl- $(1 \rightarrow 2)-3,4-O-\left(2^{\prime}, 3^{\prime}\right.$-diethoxybutane-2', $3^{\prime}$-diyl)-1-thio- $\alpha$-L-rhamnopyranoside (11) in $86 \%$ yield. Zemplén deacetylation of $\mathbf{1 1}$, followed by oxidation with DMSO/Ac ${ }_{2} \mathrm{O},{ }^{11}$ reduction with $\mathrm{NaBH}_{4}$, and acetylation with $\mathrm{Ac}_{2} \mathrm{O}$ in pyridine, afforded ethyl 2 - $O$-acetyl-3,4,6-tri- $O$-benzyl- $\beta$-D-mannopyranosyl- $(1 \longrightarrow 2)$ 3,4-O-(2',3'-diethoxybutane-2', $3^{\prime}$-diyl $)-1$-thio- $\alpha$-L-rhamnopyranoside (14) in $62 \%$ yield for four steps. In compound 11, the chemical shifts of $\mathrm{H}-1^{\prime}$ and $\mathrm{H}-2^{\prime}$ appear at $4.58 \mathrm{ppm}(\mathrm{d}, J=8.4 \mathrm{~Hz})$ and $5.07 \mathrm{ppm}(\mathrm{t}$, $J=8.4 \mathrm{~Hz}$ ), while in $\mathbf{1 4}, \mathrm{H}-1^{\prime}$ and $\mathrm{H}-4^{\prime}$ appear at $5.10 \mathrm{ppm}(J<1.0 \mathrm{~Hz})$ and $5.76 \mathrm{ppm}(\mathrm{d}, J=2.6 \mathrm{~Hz})$, respectively. This indicated a successful transformation of the glucose derivative into the corresponding mannose derivative. ${ }^{12}$ Hydrolysis of $\mathbf{1 4}$ with aqueous $90 \%$ TFA $(\rightarrow \mathbf{1 5})$, followed by regioselective 4-OH glycosylation with 3,4,6-tri- $O$-acetyl-2-deoxy-2-phthalimido- $\beta$-Dglucopyranosyl trichloroacetimidate $(\mathbf{1 6})^{13}(\rightarrow \mathbf{1 7})$ and acetylation with $\mathrm{Ac}_{2} \mathrm{O}$ in pyridine, delivered trisaccharide donor ethyl 2-O-acetyl-3,4,6-tri- $O$-benzyl- $\beta$-D-mannopyranosyl-( $1 \rightarrow 2)$-[3,4,6-tri- $O$-acetyl-2-deoxy-2-phthalimido- $\beta$-D-glucopyranosyl- $(1 \rightarrow 4)]-3-O$-acetyl-1-thio- $\alpha$-Lrhamnopyranoside (18) in an overall yield of 55\% for three steps. The characteristic peaks corresponding to $\mathrm{H}-1^{\mathrm{III}}, \mathrm{H}-4^{\mathrm{I}}$, and $\mathrm{H}-3^{\mathrm{I}}$ in the ${ }^{1} \mathrm{H}$ NMR spectrum of 18 that appear at $5.48 \mathrm{ppm}(\mathrm{d}, J=8.3 \mathrm{~Hz}), 3.79 \mathrm{ppm}(\mathrm{t}$, $J=9.5 \mathrm{~Hz})$, and $4.73 \mathrm{ppm}(\mathrm{dd}, J=9.5,3.1 \mathrm{~Hz})$, respectively, further confirmed the desired selectivity on C-4 in the above glycosylation.

Condensation of trisaccharide donor $\mathbf{1 8}$ and disaccharide acceptor 7 in $\mathrm{CH}_{2} \mathrm{Cl}_{2}$, using NIS/TMSOTf as cocatalyst, stereoselectively gave pentasaccharide 19 in good isolated yield. 2D NMR spectra of 19 clearly showed 5 H-1s (H-1 ${ }^{\mathrm{I}}$ : 4.94 ppm; H-1 ${ }^{\mathrm{II}}$ : 5.52 ppm; H$1^{\mathrm{III}}$ : $5.29 \mathrm{ppm}$; H-1 ${ }^{\mathrm{IV}}$ : $4.36 \mathrm{ppm} ; \mathrm{H}-1^{\mathrm{V}}$ : $\left.5.47 \mathrm{ppm}\right)$ and 5 C-1s (C-1 ${ }^{\text {I: }} 96.80$ ppm; C- $1^{\mathrm{II}}$ : $95.47 \mathrm{ppm}$; C-1 ${ }^{\mathrm{III}}$ : 97.58 ppm; C-1 ${ }^{\text {IV }}: 100.04$ ppm; C-1 ${ }^{\mathrm{V}}$ : 97.37 ppm), which are consistent with the desired structure. No $\beta$ isomer was isolated from this reaction. Acetal cleavage of compound 19 was smoothly conducted with $90 \%$ aqueous acetic acid under reflux, and the intermediate was subse-

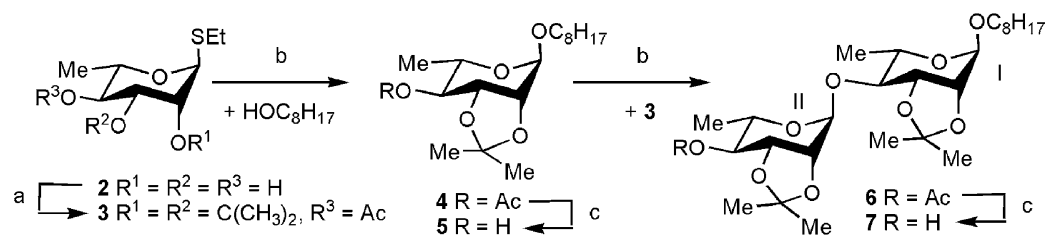

Scheme 1. Synthesis of disaccharide acceptor 7. Reagents and conditions: (a) 2,2,-dimethoxypropane, acetone, TsOH, rt, 91\%; (b) NIS, TMSOTf, $\mathrm{CH}_{2} \mathrm{Cl}_{2},-20{ }^{\circ} \mathrm{C}$; (c) $\mathrm{NaOMe}, \mathrm{MeOH}, \mathrm{rt}, 86 \%$ for 5 from $3,83 \%$ for 7 from 4. 


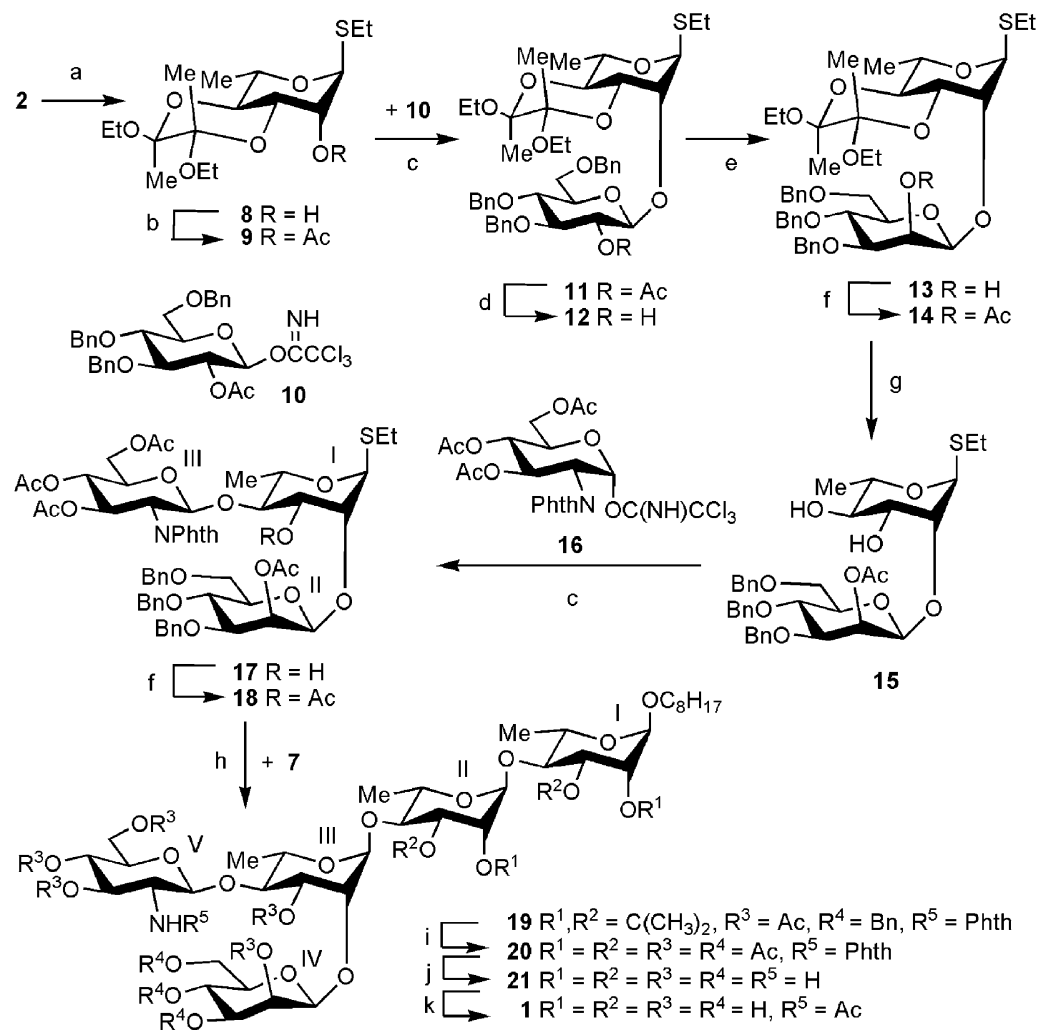

Scheme 2. Synthesis of pentasaccharide 1. Reagents and conditions: (a) triethyl orthoformate, butanedione, TsOH, EtOH, rt, 79\%; (b) Ac 2 O, Py; (c) TMSOTf, $\mathrm{CH}_{2} \mathrm{Cl}_{2}, 0{ }^{\circ} \mathrm{C}, 86 \%$ for $11,65 \%$ for 17 at $-60{ }^{\circ} \mathrm{C}$; (d) $\mathrm{NaOMe}, \mathrm{MeOH}$, rt, $83 \%$; (e) $\mathrm{Ac}_{2} \mathrm{O}$, DMSO, rt; $\mathrm{NaBH}_{4}, 1: 1 \mathrm{CH}_{2} \mathrm{Cl}{ }_{2}-\mathrm{MeOH}^{\circ} 0{ }^{\circ} \mathrm{C}$; (f) $\mathrm{Ac}_{2} \mathrm{O}$, Py, $75 \%$ for $\mathbf{1 4}$ (from 12), 100\% for 18; (g) 90\% TFA aqueous solution, rt, $85 \%$; (h) NIS/TMSOTf, $-20{ }^{\circ} \mathrm{C}, 80 \%$; (i) $90 \%$ AcOH aq, reflux; $20 \%$ $\mathrm{Pd}(\mathrm{OH})_{2} / \mathrm{C}, \mathrm{H}_{2} ; \mathrm{Ac}_{2} \mathrm{O}$, Py; (j) $\mathrm{NH}_{3}, 4: 1 \mathrm{MeOH}-\mathrm{CH}_{2} \mathrm{Cl}_{2}, 6$ days; (k) $\mathrm{Ac}_{2} \mathrm{O}$, Py; $\mathrm{NaOMe}, \mathrm{MeOH}, 59 \%$ based on 19.

quently debenzylated with $\mathrm{H}_{2}$ and $\mathrm{Pd}(\mathrm{OH})_{2} / \mathrm{C}$. The above residue was further treated with $\mathrm{NH}_{3}$-saturated $\mathrm{MeOH}$ for 6 days to deprotect acetyl and phthalyl protecting groups. Global N,O-acetylation with acetic anhydride in pyridine, followed by O-deacetylation with $\mathrm{NaOMe}$ in $\mathrm{MeOH}$, furnished pentasaccharide derivative $\mathbf{1}$ as a white foam in 59\% yield from $\mathbf{1 9}$.

The differentiation-inducing activity of pentasaccharide 1 in the HL-60 cell line was preliminarily studied according to the published method. ${ }^{4,14}$ The results are summarized in Table 1. Our experiments indicate that compound 1 can induce NBT reduction and is a dosedependent differentiation inducer for HL-60 cells. At a

Table 1. Compound 1 induced differentiation activities of HL-60 cells

\begin{tabular}{lrl}
\hline Concentrations & & NBT reduction $\left(\mathrm{A}_{560 \mathrm{~nm}} / 10^{6} \text { cells }\right)^{\mathrm{a}}$ \\
\hline DEME & 0 & $0.093 \pm 0.025^{\mathrm{b}}$ \\
ATRA $(\mu \mathrm{mol} / \mathrm{L})$ & 1 & $0.191 \pm 0.006^{\mathrm{c}}$ \\
& 1 & $0.095 \pm 0.003^{\mathrm{b}, \mathrm{c}}$ \\
Compound 1 $(\mu \mathrm{g} / \mathrm{mL})$ & 10 & $0.130 \pm 0.003^{\mathrm{b}, \mathrm{c}}$ \\
& 20 & $0.167 \pm 0.005^{\mathrm{b}, \mathrm{c}}$ \\
& 50 & $0.212 \pm 0.003^{\mathrm{b}, \mathrm{c}}$ \\
\hline
\end{tabular}

$\overline{{ }^{a}}$ Data are presented as means \pm SD from three separate experiments; $\rho$-values are calculated using one-factor analysis of variance with one-way ANOVA.

${ }^{\mathrm{b}} \rho^{*}<0.01$ compared with the negative control.

${ }^{\mathrm{c}} \rho^{*}<0.01$ compared with the positive control. dosage of $50 \mu \mathrm{g} / \mathrm{mL}$, compound 1 showed the same inducing activity as the commonly used positive control (ATRA).

In conclusion, we have prepared a pentasaccharide derivative representing the natural latosillan repeating unit. In this convergent synthesis, a $\beta$-D-mannose unit was introduced by oxidation-reduction of a $\beta$-D-glucosyl 2-OH group using $\mathrm{Ac}_{2} \mathrm{O} / \mathrm{DMSO}-\mathrm{NaBH}_{4}$ conditions. L-Rhamnosyl thioglycosides were used as donors and provided good stereo outcomes in generating the $\alpha$-glycosidic bond in NIS/TMSOTf-catalyzed glycosylations. The compound prepared showed acceptable differentiation-inducing activity on HL-60 cell lines at the dosages of $10-50 \mu \mathrm{g} / \mathrm{mL}$. These results should be valuable in cell differentiation-related SAR studies. Synthesis and bioactivity studies regarding this pentasaccharide linear oligomer and dendrimer are currently under investigation in our group.

\section{Experimental}

\subsection{General}

Optical rotations were determined at $25^{\circ} \mathrm{C}$ with a Perkin-Elmer Model 241-Mc automatic polarimeter, and 
$[\alpha]_{\mathrm{D}}$-values are in units of $10^{-1} \mathrm{deg}^{2} \mathrm{~cm}^{-1}$. ${ }^{1} \mathrm{H}$ NMR, ${ }^{13} \mathrm{C}$ NMR and ${ }^{1} \mathrm{H}-{ }^{1} \mathrm{H},{ }^{1} \mathrm{H}-{ }^{13} \mathrm{C}$ COSY spectra were recorded with a Bruker ARX 400 spectrometer for solutions in $\mathrm{CDCl}_{3}$ or $\mathrm{CD}_{3} \mathrm{OD}$. Chemical shifts are given in parts per million downfield from internal $\mathrm{Me}_{4} \mathrm{Si}$. Mass spectra were measured using a MALDITOF-MS with $\alpha$-cyano-4-hydroxycinnamic acid (CCA) as matrix. Thin-layer chromatography (TLC) was performed on silica gel $\mathrm{HF}_{254}$ with detection by charring with $30 \%$ (v/v) $\mathrm{H}_{2} \mathrm{SO}_{4}$ in $\mathrm{MeOH}$ or in some cases by UV detector. Column chromatography was conducted by elution of a column of silica gel (100-200 mesh) with EtOAc-petroleum ether $\left(60-90^{\circ} \mathrm{C}\right)$ as the eluent. Solutions were concentrated at $<60^{\circ} \mathrm{C}$ under reduced pressure.

\subsection{Octyl 2,3-O-isopropylidene- $\alpha$-L-rhamnopyranoside} (5)

To a solution of compound $3(5.80 \mathrm{~g}, 20.00 \mathrm{mmol})$ and 1-octanol $(2.90 \mathrm{~mL}, \quad 18.26 \mathrm{mmol})$ in dry $\mathrm{CH}_{2} \mathrm{Cl}_{2}$ (50 mL) was added $4 \AA$ molecular sieves $(3 \mathrm{~g})$. The mixture was stirred at $-20{ }^{\circ} \mathrm{C}$ for 20 min under an $\mathrm{N}_{2}$ atmosphere, then $N$-iodosuccinimide $(7.35 \mathrm{~g}, 30.00 \mathrm{mmol})$ and TMSOTf $(100 \mu \mathrm{L}, 0.55 \mathrm{mmol})$ were added. The mixture was stirred under these conditions for $30 \mathrm{~min}$, quenched by $\mathrm{Et}_{3} \mathrm{~N}$, diluted with $\mathrm{CH}_{2} \mathrm{Cl}_{2}(100 \mathrm{~mL})$, and washed with water $(2 \times 20 \mathrm{~mL})$. The organic phase was dried over $\mathrm{Na}_{2} \mathrm{SO}_{4}$ and concentrated under diminished pressure to give crude product, which was subsequently dissolved in $\mathrm{MeOH}(100 \mathrm{~mL})$. To this mixture was added $\mathrm{NaOMe}(1.0 \mathrm{M}$, kept $\mathrm{pH}$ at 9-10) at rt, stirred under these conditions for $3 \mathrm{~h}$, then neutralized with Amberlite IR-120 $\left(\mathrm{H}^{+}\right)$. The mixture was filtered, and the filtrate was concentrated. The residue was purified by silica gel column chromatography (4:1 petroleum ether-EtOAc) to give 5 as a white foam $(5.44 \mathrm{~g}, 86 \%)$ : $[\alpha]_{\mathrm{D}}^{25}-49\left(c 1.2, \mathrm{CHCl}_{3}\right) ;{ }^{1} \mathrm{H}$ NMR $\left(400 \mathrm{MHz}, \mathrm{CDCl}_{3}\right)$ $\delta 4.98(\mathrm{~s}, 1 \mathrm{H}, \mathrm{H}-1), 4.19(\mathrm{dd}, 1 \mathrm{H}, J 3.5,1.7 \mathrm{~Hz}, \mathrm{H}-2)$, 4.14 (dd, 1H, J 10.0, 3.5 Hz, H-3), 3.76-3.85 (m, 2H, $\mathrm{H}-4, \mathrm{H}-5), 3.66,3.42\left(2 \mathrm{dt}, 2 \mathrm{H}, J 6.5,9.7 \mathrm{~Hz}, \mathrm{OCH}_{2}\right)$, 1.59-1.57 (m, 2H, $\left.\mathrm{OCH}_{2} \mathrm{CH}_{2}\right), 1.55,1.34(2 \mathrm{~s}, 6 \mathrm{H}$, $\left.\left(\mathrm{CH}_{3}\right)_{2} \mathrm{C}\right), 1.29-1.26\left(\mathrm{~m}, 10 \mathrm{H}, 5 \mathrm{CH}_{2}\right), 1.16(\mathrm{~d}, 3 \mathrm{H}, J$ $6.3 \mathrm{~Hz}, \mathrm{H}-6), 0.89$ (t, $3 \mathrm{H}, J 7.0 \mathrm{~Hz}, \mathrm{CH}_{3}$ ). Anal. Calcd for $\mathrm{C}_{17} \mathrm{H}_{32} \mathrm{O}_{5}$ : C, 64.53; H, 10.19. Found: $\mathrm{C}, 64.28 ; \mathrm{H}$, 10.25 .

\subsection{Octyl 4- $O$-acetyl-2,3-O-isopropylidene- $\alpha$-L-rhamno- pyranosyl-( $1 \rightarrow 4)$-2,3- $O$-isopropylidene- $\alpha$-L-rhamno- pyranoside (6)}

To a solution of compounds $3(1.60 \mathrm{~g}, 5.5 \mathrm{mmol})$ and 5 $(1.58 \mathrm{~g}, 5.0 \mathrm{mmol})$ in dry $\mathrm{CH}_{2} \mathrm{Cl}_{2}(20 \mathrm{~mL})$ was added $4 \AA$ molecular sieves $(3 \mathrm{~g})$. The mixture was stirred at $-20{ }^{\circ} \mathrm{C}$ for $20 \mathrm{~min}$ under an $\mathrm{N}_{2}$ atmosphere, then $\mathrm{N}$ iodosuccinimide $(2.02 \mathrm{~g}, 8.25 \mathrm{mmol})$ and TMSOTf $(50 \mu \mathrm{L}, 0.28 \mathrm{mmol})$ were added. The mixture was stir- red under these conditions for $30 \mathrm{~min}$, quenched by $\mathrm{Et}_{3} \mathrm{~N}$, and concentrated. The residue was purified by silica gel column chromatography $(5: 1$ petroleum ether-EtOAc) to give 6 as a syrup $(2.45 \mathrm{~g}, 90 \%):[\alpha]_{\mathrm{D}}^{25}$ -67 (c 1, $\left.\mathrm{CHCl}_{3}\right) ;{ }^{1} \mathrm{H}$ NMR $\left(400 \mathrm{MHz}, \mathrm{CDCl}_{3}\right) \delta$ $5.63\left(\mathrm{~s}, 1 \mathrm{H}, \mathrm{H}-1^{\prime}\right), 4.95(\mathrm{~s}, 1 \mathrm{H}, \mathrm{H}-1), 4.88(\mathrm{dd}, 1 \mathrm{H}, J$ 10.1, $\left.7.9 \mathrm{~Hz}, \mathrm{H}-4^{\prime}\right), 4.21$ (dd, $1 \mathrm{H}, J 7.1,5.6 \mathrm{~Hz}, \mathrm{H}-3$ ), $4.19(\mathrm{~d}, 1 \mathrm{H}, J 5.6 \mathrm{~Hz}, \mathrm{H}-2), 4.17(\mathrm{dd}, 1 \mathrm{H}, J 7.9$, $\left.5.8 \mathrm{~Hz}, \mathrm{H}-3^{\prime}\right), 4.10\left(\mathrm{~d}, 1 \mathrm{H}, J 5.8 \mathrm{~Hz}, \mathrm{H}-2^{\prime}\right), 3.76-3.60$ $\left(\mathrm{m}, 2 \mathrm{H}, \mathrm{H}-5, \mathrm{H}-5^{\prime}\right), 3.67,3.41(2 \mathrm{dt}, 2 \mathrm{H}, J 9.6,6.6 \mathrm{~Hz}$, $\left.\mathrm{OCH}_{2}\right), 3.59$ (dd, $1 \mathrm{H}, J$ 9.9, $\left.7.1 \mathrm{~Hz}, \mathrm{H}-4\right), 2.10$ (s, $\left.3 \mathrm{H}, \mathrm{CH}_{3} \mathrm{CO}\right), 1.60-1.58\left(\mathrm{~m}, 2 \mathrm{H}, \mathrm{OCH}_{2} \mathrm{CH}_{2}\right), 1.55$, $1.53, \quad 1.36, \quad 1.33 \quad\left(4 \mathrm{~s}, 4 \times 3 \mathrm{H}, 2\left(\mathrm{CH}_{3}\right)_{2} \mathrm{C}\right), \quad 1.30-1.26$ $\left(\mathrm{m}, 10 \mathrm{H}, 5 \mathrm{CH}_{2}\right), 1.21,1.14(\mathrm{~d}, 2 \times 3 \mathrm{H}, J 6.3 \mathrm{~Hz}, \mathrm{H}-6$, $\left.\mathrm{H}-6^{\prime}\right), 0.89$ (t, $3 \mathrm{H}, J 7.0 \mathrm{~Hz}, \mathrm{CH}_{3}$ ). Anal. Calcd for $\mathrm{C}_{28} \mathrm{H}_{48} \mathrm{O}_{10}$ : C, 61.74; $\mathrm{H}, 8.88$. Found: $\mathrm{C}, 62.02 ; \mathrm{H}$, 8.96 .

3.4. Octyl 2,3- $O$-isopropylidene- $\alpha$-L-rhamnopyranosyl$(1 \rightarrow 4)-2,3-O$-isopropylidene- $\alpha$-L-rhamnopyranoside (7)

Removal of the acetyl group from compound 6 ( $2.40 \mathrm{~g}$, $4.41 \mathrm{mmol})$, as described in the preparation of 5 , gave 7 as a white foam $(2.03 \mathrm{~g}, 92 \%):[\alpha]_{\mathrm{D}}^{25}-6\left(c 1, \mathrm{CHCl}_{3}\right) ;{ }^{1} \mathrm{H}$ NMR $\left(400 \mathrm{MHz}, \mathrm{CDCl}_{3}\right) \delta 5.60\left(\mathrm{~s}, 1 \mathrm{H}, \mathrm{H}-1^{\prime}\right), 4.95(\mathrm{~s}$, $1 \mathrm{H}, \mathrm{H}-1), 4.23$ (dd, 1H, J 7.0, $5.6 \mathrm{~Hz}, \mathrm{H}-3), 4.19$ (d, $1 \mathrm{H}, J 5.6 \mathrm{~Hz}, \mathrm{H}-2), 4.10\left(\mathrm{~d}, 1 \mathrm{H}, J 5.7 \mathrm{~Hz}, \mathrm{H}-2^{\prime}\right), 4.01$ $\left(\mathrm{dd}, 1 \mathrm{H}, J\right.$ 7.5, $\left.5.7 \mathrm{~Hz}, \mathrm{H}-3^{\prime}\right), 3.69-3.56(\mathrm{~m}, 4 \mathrm{H}, \mathrm{H}-4$, H-4 $\left.{ }^{\prime}, \mathrm{H}-5, \mathrm{H}-5^{\prime}\right), 3.42-3.39$ (m, $\left.2 \mathrm{H}, \mathrm{OCH}_{2}\right), 1.55,1.53$, $1.36,1.33\left(4 \mathrm{~s}, 4 \times 3 \mathrm{H},\left(\mathrm{CH}_{3}\right)_{2} \mathrm{C}\right), 1.60-1.58(\mathrm{~m}, 2 \mathrm{H}$, $\left.\mathrm{CH}_{2}\right), 1.32-1.28\left(\mathrm{~m}, 10 \mathrm{H}, 5 \mathrm{CH}_{2}\right), 1.27,1.25(2 \mathrm{~d}$, $\left.2 \times 3 \mathrm{H}, J 6.3 \mathrm{~Hz}, \mathrm{H}-6, \mathrm{H}-6^{\prime}\right), 0.89(\mathrm{t}, 3 \mathrm{H}, J 7.7 \mathrm{~Hz}$, $\mathrm{CH}_{3}$ ). Anal. Calcd for $\mathrm{C}_{26} \mathrm{H}_{46} \mathrm{O}_{9}: \mathrm{C}, 62.13 ; \mathrm{H}, 9.22$. Found: C, 61.89; H, 9.14.

\subsection{Ethyl 3,4-O-(2',3'-diethoxybutane-2', $3^{\prime}$-diyl)-1-thio- $\alpha$-L-rhamnopyranoside (8)}

To a solution of compound $2(4.20 \mathrm{~g}, 20.17 \mathrm{mmol})$ in EtOH $(50 \mathrm{~mL})$ was added triethyl orthoformate $(21.3 \mathrm{~mL}, \quad 161 \mathrm{mmol})$, butanedione $(5.3 \mathrm{~mL}, \quad 60.39$ $\mathrm{mmol})$, and $\mathrm{TsOH}(\mathrm{pH} 3)$ at $\mathrm{rt}$. The mixture was stirred under these conditions for $1 \mathrm{~h}$, quenched by $\mathrm{Et}_{3} \mathrm{~N}$, and concentrated. The residue was purified by silica gel column chromatography (6:1 petroleum ether-EtOAc) to give foamy $8(5.60 \mathrm{~g}, 79 \%)$. To confirm the structure, compound $8(30 \mathrm{mg})$ was acetylated with $\mathrm{Ac}_{2} \mathrm{O}(1 \mathrm{~mL})$ in pyridine $(2 \mathrm{~mL})$ affording 9 as a syrup, quantitatively: $[\alpha]_{\mathrm{D}}^{25}-5\left(c 1, \mathrm{CHCl}_{3}\right) ;{ }^{1} \mathrm{H}$ NMR $\left(400 \mathrm{MHz}, \mathrm{CDCl}_{3}\right) \delta$ $5.18(\mathrm{~d}, 1 \mathrm{H}, J 1.4 \mathrm{~Hz}, \mathrm{H}-1), 5.13(\mathrm{dd}, 1 \mathrm{H}, J 3.2$, $1.4 \mathrm{~Hz}, \mathrm{H}-2), 4.15$ (m, 1H, H-5), 4.07 (dd, 1H, $J 10.1$, $3.2 \mathrm{~Hz}, \mathrm{H}-3), 3.73$ (t, 1H, J 10.1 Hz, H-4), 3.51-3.49 (m, $\left.2 \times 2 \mathrm{H}, 2 \mathrm{OCH}_{2}\right), 2.64-2.62\left(\mathrm{~m}, 2 \mathrm{H}, \mathrm{SCH} \mathrm{H}_{2}\right), 2.13(\mathrm{~s}$, $\left.3 \mathrm{H}, \mathrm{CH}_{3} \mathrm{CO}\right), 1.26-1.20\left(\mathrm{~m}, 18 \mathrm{H}, \mathrm{H}-6\right.$ and $\left.5 \mathrm{CH}_{3}\right)$. For 8: Anal. Calcd for $\mathrm{C}_{16} \mathrm{H}_{30} \mathrm{O}_{6} \mathrm{~S}: \mathrm{C}, 54.83 ; \mathrm{H}, 8.63$. Found: C, 55.01; H, 8.72. 
3.6. Ethyl 2-O-acetyl-3,4,6-tri- $O$-benzyl-p-D-glucopyranosyl-(1 $\rightarrow 2)-3,4-O-\left(2^{\prime}, 3^{\prime}\right.$-diethoxybutane-2', $3^{\prime}$-diyl $)-1-$ thio- $\alpha$-L-rhamnopyranoside (11)

To a solution of compound $\mathbf{8}(1.76 \mathrm{~g}, 5.02 \mathrm{mmol})$ and compound $10(3.84 \mathrm{~g}, 6.02 \mathrm{mmol})$ in dry $\mathrm{CH}_{2} \mathrm{Cl}_{2}$ $(30 \mathrm{~mL})$ was added $4 \AA$ molecular sieves $(3 \mathrm{~g})$ at $0{ }^{\circ} \mathrm{C}$ under an $\mathrm{N}_{2}$ atmosphere. The mixture was stirred under these conditions for $20 \mathrm{~min}$, then TMSOTf $(21 \mu \mathrm{L}$, $0.12 \mathrm{mmol}$ ) was added. The reaction mixture was stirred under these conditions for $1 \mathrm{~h}$, quenched by $\mathrm{Et}_{3} \mathrm{~N}$, and concentrated. The residue was purified by silica gel column chromatography ( $4: 1$ petroleum ether-EtOAc) to give $11(3.56 \mathrm{~g}, 86 \%)$ as a white foam: $[\alpha]_{\mathrm{D}}^{25}-29(c 1.5$, $\left.\mathrm{CHCl}_{3}\right) ;{ }^{1} \mathrm{H}$ NMR $\left(400 \mathrm{MHz}, \mathrm{CDCl}_{3}\right) \delta 7.40-7.28(\mathrm{~m}$, $15 \mathrm{H}, \mathrm{Ph} H), 5.42(\mathrm{~d}, 1 \mathrm{H}, J 1.1 \mathrm{~Hz}, \mathrm{H}-1), 5.07(\mathrm{t}, 1 \mathrm{H}, J$ $\left.8.4 \mathrm{~Hz}, \mathrm{H}-2^{\prime}\right), 4.80,4.77,4.68,4.56(4 \mathrm{~d}, 4 \mathrm{H}, J 10.2 \mathrm{~Hz}$, $\left.2 \mathrm{PhCH}_{2}\right), 4.58\left(\mathrm{dd}, 1 \mathrm{H}, J 8.4 \mathrm{~Hz}, \mathrm{H}^{\prime} 1^{\prime}\right), 4.55(\mathrm{~s}, 2 \mathrm{H}$, $\mathrm{PhCH}_{2}$ ), 4.05-4.03 (m, 1H, H-5), 3.93 (dd, $1 \mathrm{H}, J 10.2$, $3.0 \mathrm{~Hz}, \mathrm{H}-3), 3.86$ (dd, 1H, J 3.0, $1.1 \mathrm{~Hz}, \mathrm{H}-2), 3.69-$ 3.64 (m, 5H, H-4, H-3', H-4', H-5', H-6a'), 3.48-3.44 $\left(\mathrm{m}, 5 \mathrm{H}, \quad \mathrm{H}-6 \mathrm{~b}^{\prime}, 2 \mathrm{OCH}_{2} \mathrm{CH}_{3}\right), 2.55-3.53(\mathrm{~m}, 2 \mathrm{H}$, $\left.\mathrm{SCH}_{2} \mathrm{CH}_{3}\right), 2.15\left(\mathrm{~s}, 3 \mathrm{H}, \mathrm{CH}_{3} \mathrm{CO}\right), 1.23-1.11(\mathrm{~m}, 18 \mathrm{H}$, $\mathrm{H}-6,5 \mathrm{CH}_{3}$ ). Anal. Calcd for $\mathrm{C}_{45} \mathrm{H}_{60} \mathrm{O}_{12} \mathrm{~S}: \mathrm{C}, 65.51 ; \mathrm{H}$, 7.33. Found: C, 65.82; H, 7.24.

\subsection{Ethyl 3,4,6-tri- $O$-benzyl- $\beta$-D-glucopyranosyl-( $1 \rightarrow 2)$ - $3,4-O-\left(2^{\prime}, 3^{\prime}\right.$-diethoxybutane-2',3'-diyl)-1-thio- $\alpha-\mathrm{L}-$ rhamnopyranoside (12)}

Removal of the acetyl group from compound $\mathbf{1 1}$ (3.20 g, $3.88 \mathrm{mmol}$ ) as described in the preparation of $\mathbf{5}$ gave $\mathbf{1 2}$ as a white foam $(2.52 \mathrm{~g}, 83 \%)$ : $[\alpha]_{\mathrm{D}}^{25}-17\left(c 2, \mathrm{CHCl}_{3}\right) ;{ }^{1} \mathrm{H}$ NMR $\left(400 \mathrm{MHz}, \mathrm{CDCl}_{3}\right) \delta 7.45-7.28(\mathrm{~m}, 15 \mathrm{H}, \mathrm{Ph} H)$, $5.34(\mathrm{~s}, 1 \mathrm{H}, \mathrm{H}-1), 5.07,4.86,4.79,4.56,4.53,4.50$ (6d, $\left.6 \mathrm{H}, J 10.2 \mathrm{~Hz}, \mathrm{PhCH}_{2}\right), 4.42\left(\mathrm{~d}, 1 \mathrm{H}, J 7.3 \mathrm{~Hz}, \mathrm{H}-1^{\prime}\right)$, 4.14-4.12 (m, 1H, H-5), 4.01 (dd, 1H, J 10.0, $2.9 \mathrm{~Hz}, \mathrm{H}-$ 3), 3.98 (d, $1 \mathrm{H}, J 2.9 \mathrm{~Hz}, \mathrm{H}-2), 3.66-3.61$ (m, 4H, H-2', $\mathrm{H}-3^{\prime}, \mathrm{H}-4^{\prime}, \mathrm{H}-5^{\prime}$ ), 3.53-3.48 (m, 6H, H-6', $\mathrm{OCH}_{2} \mathrm{CH}_{3}$ ), 2.62-2.59 (m, 2H, SCH $\left.\mathrm{CH}_{3}\right), 1.23-1.11(\mathrm{~m}, 18 \mathrm{H}, \mathrm{H}-6$, $\mathrm{CH}_{3}$ ). MALDITOF-MS: calcd for $\mathrm{C}_{43} \mathrm{H}_{58} \mathrm{O}_{11} \mathrm{~S}, \mathrm{~m} / \mathrm{z}$ 782; found: $m / z$ 805.3 (M+Na) ${ }^{+}$. Anal. Calcd for $\mathrm{C}_{43} \mathrm{H}_{58} \mathrm{O}_{11} \mathrm{~S}: \mathrm{C}, 65.96 ; \mathrm{H}, 7.47$. Found: C, 66.25; H, 7.41.

\subsection{Ethyl 2-O-acetyl-3,4,6-tri- $O$-benzyl- $\beta$-D-manno- pyranosyl-(1 $\rightarrow 2)-3,4-O-\left(2^{\prime}, 3^{\prime}\right.$-diethoxybutane-2', $3^{\prime}$-diyl)- 1-thio- $\alpha$-L-rhamnopyranoside (14)}

A solution of compound $12(1.51 \mathrm{~g}, 1.93 \mathrm{mmol})$ in 1,2 $\mathrm{Ac}_{2} \mathrm{O}-\mathrm{DMSO}(15 \mathrm{~mL})$ was kept at room temperature until all starting materials were consumed based on TLC monitoring. The mixture was diluted with $\mathrm{CH}_{2} \mathrm{Cl}_{2}$ $(90 \mathrm{~mL})$ and washed with water $(3 \times 40 \mathrm{~mL})$. The organic layer was dried over $\mathrm{MgSO}_{4}$ and evaporated. To the above-mentioned crude residue in $1: 1 \mathrm{CH}_{2} \mathrm{Cl}_{2}-\mathrm{MeOH}$ $(20 \mathrm{~mL})$ at $0{ }^{\circ} \mathrm{C}$ was added $\mathrm{NaBH}_{4}(700 \mathrm{mg})$ in one portion. The reaction mixture was stirred at $\mathrm{rt}$ for $6 \mathrm{~h}$, then diluted with $\mathrm{CH}_{2} \mathrm{Cl}_{2}$, and the organic phase was successively washed with water, aq $\mathrm{NaHCO}_{3}$, and brine. The organic solvent was evaporated in vacuum, and the crude residue was acetylated with $\mathrm{Ac}_{2} \mathrm{O}(5 \mathrm{~mL})$ in dry pyridine $(10 \mathrm{~mL})$ at $\mathrm{rt}$ for $12 \mathrm{~h}$, then concentrated to dryness with the help of toluene. The residue was purified by silica gel column chromatography (5:1 petroleum ether-EtOAc) to yield $\mathbf{1 4}(1.20 \mathrm{~g}, 75 \%$ for three steps) as a white foam: $[\alpha]_{\mathrm{D}}^{25}-52\left(\mathrm{c} 2, \mathrm{CHCl}_{3}\right) ;{ }^{1} \mathrm{H}$ NMR $\left(400 \mathrm{MHz}, \mathrm{CDCl}_{3}\right) \delta 7.40-7.28(\mathrm{~m}, 15 \mathrm{H}, \mathrm{PhH}), 5.76$ (br d, 1H, J $2.6 \mathrm{~Hz}, \mathrm{H}-2^{\prime}$ ), 5.32 (d, 1H, $J 1.1 \mathrm{~Hz}, \mathrm{H}-1$ ), 5.10 (br s, $1 \mathrm{H}, \mathrm{H}-1^{\prime}$ ), 4.85, 4.80, 4.66, 4.58, 4.50, 4.47 (6d, $\left.6 \mathrm{H}, J 10.2 \mathrm{~Hz}, \mathrm{PhCH}_{2}\right), 4.16-4.14\left(\mathrm{~m}, 1 \mathrm{H}, \mathrm{H}-4^{\prime}\right)$, 4.10-4.07 (m, 1H, H-5), $4.01(\mathrm{dd}, 1 \mathrm{H}, J 10.2,2.6 \mathrm{~Hz}$, H-3'), 3.86 (dd, 1H, J 3.0, 1.1 Hz, H-2), 3.69-3.64 (m, $\left.5 \mathrm{H}, \mathrm{H}-4, \mathrm{H}-3, \mathrm{H}-4^{\prime}, \mathrm{H}-5^{\prime}, \mathrm{H}-6 \mathrm{a}^{\prime}\right), 3.49-3.44$ (m, 5H, H$\left.6 \mathrm{~b}^{\prime}, \mathrm{OCH}_{2}\right), 2.57-2.54\left(\mathrm{~m}, 2 \mathrm{H}, \mathrm{SCH}_{2}\right), 2.15(\mathrm{~s}, 3 \mathrm{H}$, $\left.\mathrm{CH}_{3} \mathrm{CO}\right), 1.23-1.11\left(\mathrm{~m}, 18 \mathrm{H}, \mathrm{H}-6,5 \mathrm{CH}_{3}\right)$. Anal. Calcd for $\mathrm{C}_{45} \mathrm{H}_{60} \mathrm{O}_{12} \mathrm{~S}$ : C, 65.51; H, 7.33. Found: C, 65.77; H, 7.29 .

\subsection{Ethyl 2- $O$-acetyl-3,4,6-tri- $O$-benzyl- $\beta$-D-manno- pyranosyl-(1 $\rightarrow$ 2)-1-thio- $\alpha$-L-rhamnopyranoside $(15)$}

Compound 14 (1.15 g, $1.39 \mathrm{mmol}$ ) was dissolved in 90\% aqueous TFA $(8 \mathrm{~mL})$, stirred at $\mathrm{rt}$ for $30 \mathrm{~min}$, and coevaporated with toluene to dryness under diminished pressure. The residue was purified by silica gel column chromatography (2:1 petroleum ether-EtOAc) to give $15(810 \mathrm{mg}, 85 \%)$ as a colorless syrup: $[\alpha]_{\mathrm{D}}^{25}-35(c 1.5$, $\mathrm{CHCl}_{3}$ ). To confirm the structure, compound 15 $(50 \mathrm{mg}, 0.07 \mathrm{mmol})$ was acetylated with $\mathrm{Ac}_{2} \mathrm{O}(0.5 \mathrm{~mL})$ in pyridine $(1 \mathrm{~mL})$ affording ethyl $2-O$-acetyl-3,4,6-tri$O$-benzyl- $\beta$-D-mannopyranosyl-( $1 \rightarrow 2)-3,4$-di- $O$-acetyl1-thio- $\alpha$-L-rhamnopyranoside, quantitatively: $[\alpha]_{\mathrm{D}}^{25}-13$ (c $1, \mathrm{CHCl}_{3}$ ); ${ }^{1} \mathrm{H}$ NMR (400 MHz, $\mathrm{CDCl}_{3}$ ) $\delta 7.40-7.28$ $(\mathrm{m}, 15 \mathrm{H}, \mathrm{Ph} H), 5.67$ (br d, $\left.1 \mathrm{H}, J 2.6 \mathrm{~Hz}, \mathrm{H}-2^{\prime}\right), 5.41$ $(\mathrm{d}, 1 \mathrm{H}, J 1.4 \mathrm{~Hz}, \mathrm{H}-1), 5.10(\mathrm{dd}, 1 \mathrm{H}, J 10.0,3.1 \mathrm{~Hz}$, $\mathrm{H}-3), 5.05(\mathrm{dd}, 1 \mathrm{H}, J 10.0,9.4 \mathrm{~Hz}, \mathrm{H}-4), 4.85,4.80$, 4.66, 4.58, 4.50, $4.47\left(6 \mathrm{~d}, 6 \times 1 \mathrm{H}, J 10.2 \mathrm{~Hz}, \mathrm{PhCH}_{2}\right)$, 4.61 (br s, 1H, H-1'), 4.26-4.24 (m, 1H, H-6a'), 4.14 $4.11(\mathrm{~m}, 1 \mathrm{H}, \mathrm{H}-5), 3.74-3.67\left(\mathrm{~m}, 3 \mathrm{H}, \mathrm{H}-2, \mathrm{H}-4^{\prime}, \mathrm{H}-\right.$ $\left.6 \mathrm{~b}^{\prime}\right), 3.64\left(\mathrm{dd}, 1 \mathrm{H}, J 10.2,2.6 \mathrm{~Hz}, \mathrm{H}-3^{\prime}\right), 3.44-3.42(\mathrm{~m}$, $\left.1 \mathrm{H}, \mathrm{H}-5^{\prime}\right), 2.56-2.53\left(\mathrm{~m}, 2 \mathrm{H}, \mathrm{SC} H_{2}\right), 2.21,2.06,2.01$ $\left(\mathrm{s}, \quad 3 \times 3 \mathrm{H}, \quad 3 \mathrm{CH}_{3} \mathrm{CO}\right), \quad 1.23-1.11(\mathrm{~m}, \quad 6 \mathrm{H}, \quad \mathrm{H}-6$, $\mathrm{SCH}_{2} \mathrm{CH}_{3}$ ). Anal. Calcd for $\mathrm{C}_{37} \mathrm{H}_{46} \mathrm{O}_{10} \mathrm{~S}$ (compound 15): C, 65.08; H, 6.79. Found: C, 64.80; H, 6.86.

\subsection{Ethyl 2-O-acetyl-3,4,6-tri- $O$-benzyl- $\beta$-D-manno- pyranosyl-( $1 \rightarrow 2)$-[3,4,6-tri- $O$-acetyl-2-deoxy-2-phthal- imido- $\beta$-D-glucopyranosyl-( $(1 \rightarrow 4)]-3-O$-acetyl-1-thio- $\alpha$-L- rhamnopyranoside (18)}

To a solution of compounds $\mathbf{1 5}(500 \mathrm{mg}, 0.73 \mathrm{mmol})$ and $16(465 \mathrm{mg}, 0.80 \mathrm{mmol})$ in dry $\mathrm{CH}_{2} \mathrm{Cl}_{2}(10 \mathrm{~mL})$ was 
added $4 \AA$ molecular sieves $(1 \mathrm{~g})$ at $-60^{\circ} \mathrm{C}$ under an $\mathrm{N}_{2}$ atmosphere. The mixture was stirred under these conditions for $20 \mathrm{~min}$, and then TMSOTf $(10 \mu \mathrm{L}, 0.06 \mathrm{mmol})$ was added and stirred for another $30 \mathrm{~min}$, quenched by $\mathrm{Et}_{3} \mathrm{~N}$. The mixture was filtered and the filtrate was concentrated. The residue was purified by silica gel column chromatography (3:1 petroleum ether-EtOAc) to give $\mathbf{1 7}$ as a white foam, which was acetylated with $\mathrm{Ac}_{2} \mathrm{O}(1 \mathrm{~mL})$ in pyridine $(3 \mathrm{~mL})$ to furnish $18(543 \mathrm{mg}, 65 \%$ for two steps) as a syrup: $[\alpha]_{\mathrm{D}}^{25}-42\left(c 1, \mathrm{CHCl}_{3}\right) ;{ }^{1} \mathrm{H}$ NMR $\left(400 \mathrm{MHz}, \mathrm{CDCl}_{3}\right) \delta$ 7.90-7.18 (m, 19H, $\left.\mathrm{PhH}\right), 5.83$ $\left(\mathrm{dd}, 1 \mathrm{H}, J 10.8,9.0 \mathrm{~Hz}, \mathrm{H}-3^{\mathrm{III}}\right), 5.67$ (br d, $1 \mathrm{H}, J$ $\left.3.0 \mathrm{~Hz}, \mathrm{H}-2^{\mathrm{II}}\right), 5.48\left(\mathrm{~d}, 1 \mathrm{H}, J 8.3 \mathrm{~Hz}, \mathrm{H}-1^{\mathrm{III}}\right), 5.28(\mathrm{~d}$, $\left.1 \mathrm{H}, J 1.4 \mathrm{~Hz}, \mathrm{H}-1^{\mathrm{I}}\right), 5.20(\mathrm{dd}, 1 \mathrm{H}, J 10.0,9.0 \mathrm{~Hz}, \mathrm{H}-$ $\left.4^{\mathrm{III}}\right), 4.87,4.77,4.57,4.55,4.53,4.49(6 \mathrm{~d}, 6 \mathrm{H}, J$ $\left.10.2 \mathrm{~Hz}, 3 \mathrm{PhCH}_{2}\right), 4.73\left(\mathrm{dd}, 1 \mathrm{H}, J 9.5,3.1 \mathrm{~Hz}, \mathrm{H}-3^{\mathrm{I}}\right)$, $4.40\left(\mathrm{dd}, 1 \mathrm{H}, J 12.3,3.7 \mathrm{~Hz}, \mathrm{H}-6 \mathrm{a}^{\mathrm{III}}\right), 4.37$ (br s, $1 \mathrm{H}$, H-1 $\left.{ }^{\mathrm{II}}\right), 4.30\left(\mathrm{dd}, 1 \mathrm{H}, J 12.3,3.7 \mathrm{~Hz}, \mathrm{H}-6 \mathrm{~b}^{\mathrm{III}}\right), 4.23$ (dd, $\left.1 \mathrm{H}, J 10.8,8.3 \mathrm{~Hz}, \mathrm{H}-2^{\mathrm{III}}\right), 4.03(\mathrm{dd}, 1 \mathrm{H}, J 1.4,3.1 \mathrm{~Hz}$, $\left.\mathrm{H}-2^{\mathrm{I}}\right), 3.98\left(\mathrm{dt}, 1 \mathrm{H}, \mathrm{H}-5^{\mathrm{III}}\right), 3.90-3.85\left(\mathrm{~m}, 1 \mathrm{H}, \mathrm{H}-5^{\mathrm{I}}\right)$, $3.79(\mathrm{t}, 1 \mathrm{H}, J 9.5 \mathrm{~Hz}, \mathrm{H}-4$ ), $3.73(\mathrm{t}, 1 \mathrm{H}, J 9.5 \mathrm{~Hz}, \mathrm{H}-$ $\left.4^{\mathrm{II}}\right), 3.70\left(\mathrm{~d}, 2 \mathrm{H}, J 3.6 \mathrm{~Hz}, \mathrm{H}-6^{\mathrm{II}}\right), 3.60(\mathrm{dd}, 1 \mathrm{H}, J 9.5$, $\left.3.0 \mathrm{~Hz}, \mathrm{H}-3^{\mathrm{II}}\right), 3.39-3.31\left(\mathrm{dt}, 1 \mathrm{H}, \mathrm{H}-5^{\mathrm{II}}\right), 2.51-2.46(\mathrm{~m}$, $\left.2 \mathrm{H}, \mathrm{SCH}_{2}\right), 2.21,2.15,2.06,2.01,1.88(5 \mathrm{~s}, 5 \times 3 \mathrm{H}$, $\left.5 \mathrm{CH}_{3} \mathrm{CO}\right), 1.24\left(\mathrm{~d}, 3 \mathrm{H}, J 6.3 \mathrm{~Hz}, \mathrm{H}-6^{\mathrm{I}}\right), 1.15(\mathrm{t}, 3 \mathrm{H}, J$ $7.3 \mathrm{~Hz}, \mathrm{CH}_{3}$ ). Anal. Calcd for $\mathrm{C}_{59} \mathrm{H}_{67} \mathrm{NO}_{20} \mathrm{~S}$ : C, 62.04; $\mathrm{H}$, 5.91. Found: $\mathrm{C}, 62.31 ; \mathrm{H}, 5.80$.

\subsection{Octyl 3,4,6-tri- $O$-acetyl-2-deoxy-2-phthalimido- $\beta$ - D-glucopyranosyl-(1 $\rightarrow$ 4)-[2-O-acetyl-3,4,6-tri- $O$-benzyl- $\beta$-D-mannopyranosyl-(1 $\rightarrow 2)]-3-O$-acetyl- $\alpha$-L-rhamno- pyranoyl-( $\rightarrow 4)-4-O$-acetyl-2,3- $O$-isopropylidene- $\alpha$-L- rhamnopyranosyl-( $1 \rightarrow 4)$-2,3- $O$-isopropylidene- $\alpha$ - - - rhamnopyranoside (19)}

Coupling of disaccharide 7 (200 mg, $0.40 \mathrm{mmol})$ and trisaccharide 18 (490 mg, $0.43 \mathrm{mmol}$ ) was carried out as described in the preparation of $\mathbf{6}$. The crude product was purified on a silica gel column (2:1 petroleum ether-EtOAc) to yield $\mathbf{1 9}$ as a foamy solid $(504 \mathrm{mg}$, $80 \%):[\alpha]_{\mathrm{D}}^{25}-100\left(c 1, \mathrm{CHCl}_{3}\right) ;{ }^{1} \mathrm{H}$ NMR $(400 \mathrm{MHz}$, $\left.\mathrm{CDCl}_{3}\right) \delta 7.78-7.18(\mathrm{~m}, 19 \mathrm{H}, \mathrm{Ph} H), 5.84(\mathrm{dd}, 1 \mathrm{H}, J$ $10.8,9.0 \mathrm{~Hz}, \mathrm{H}-3^{\mathrm{V}}$ ), 5.67 (br d, $1 \mathrm{H}, J 3.2 \mathrm{~Hz}, \mathrm{H}-2^{\mathrm{IV}}$ ), $5.52\left(\mathrm{~s}, 1 \mathrm{H}, \mathrm{H}-1^{\mathrm{II}}\right), 5.48\left(\mathrm{~d}, 1 \mathrm{H}, J 8.4 \mathrm{~Hz}, \mathrm{H}-1^{\mathrm{V}}\right), 5.28$ $\left(\mathrm{d}, 1 \mathrm{H}, J 1.6 \mathrm{~Hz}, \mathrm{H}-1^{\mathrm{III}}\right), 5.20(\mathrm{dd}, 1 \mathrm{H}, J 10.0,9.0 \mathrm{~Hz}$, $\left.\mathrm{H}-4^{\mathrm{V}}\right), 4.93\left(\mathrm{~s}, 1 \mathrm{H}, \mathrm{H}-1^{\mathrm{I}}\right), 4.87,4.80,4.64,4.57,4.53$, $4.48\left(6 \mathrm{~d}, 6 \times 1 \mathrm{H}, J 10.8 \mathrm{~Hz}, 3 \mathrm{PhCH}_{2}\right), 4.78(\mathrm{dd}, 1 \mathrm{H}, J$ 9.6, $\left.3.2 \mathrm{~Hz}, \mathrm{H}-3^{\mathrm{III}}\right), 4.41(\mathrm{dd}, 1 \mathrm{H}, J 12.4,3.0 \mathrm{~Hz}, \mathrm{H}-$ $\left.6 \mathrm{a}^{\mathrm{v}}\right), 4.37$ (br s, $\left.1 \mathrm{H}, \mathrm{H}-1^{\mathrm{IV}}\right), 4.30(\mathrm{dd}, 1 \mathrm{H}, J 12.4$, $\left.3.0 \mathrm{~Hz}, \mathrm{H}-6 \mathrm{~b}^{\mathrm{V}}\right), 4.23\left(\mathrm{dd}, 1 \mathrm{H}, J 10.8,8.4 \mathrm{~Hz}, \mathrm{H}-2^{\mathrm{V}}\right)$, $4.16\left(\mathrm{dd}, 1 \mathrm{H}, J\right.$ 7.2, $\left.5.6 \mathrm{~Hz}, \mathrm{H}-3^{\mathrm{II}}\right), 4.06(\mathrm{~d}, 1 \mathrm{H}, J$ $\left.5.6 \mathrm{~Hz}, \mathrm{H}-2^{\mathrm{II}}\right), 4.00-3.93\left(\mathrm{~m}, 4 \mathrm{H}, \mathrm{H}-2^{\mathrm{III}}, \mathrm{H}-3^{\mathrm{I}}, \mathrm{H}-5^{\mathrm{V}}\right.$, $\left.\mathrm{H}-6 \mathrm{a}^{\mathrm{IV}}\right), 3.81\left(\mathrm{t}, 3 \mathrm{H}, J 9.6 \mathrm{~Hz}, \mathrm{H}-4^{\mathrm{III}}\right), 3.79(\mathrm{t}, 3 \mathrm{H}, J$ $\left.10.0 \mathrm{~Hz}, \mathrm{H}-4^{\mathrm{IV}}\right), 3.75\left(\mathrm{~d}, 1 \mathrm{H}, J 5.6 \mathrm{~Hz}, \mathrm{H}-2^{\mathrm{I}}\right), 3.70(\mathrm{dd}$, $\left.1 \mathrm{H}, J 1.2,11.2 \mathrm{~Hz}, \mathrm{H}-6 \mathrm{~b}^{\mathrm{IV}}\right), 3.68-3.50\left(\mathrm{~m}, 6 \mathrm{H}, \mathrm{H}-4^{\mathrm{I}}\right.$, $\left.\mathrm{H}-5^{\mathrm{I}}, \mathrm{H}-5^{\mathrm{II}}, \mathrm{H}-5^{\mathrm{III}}, \mathrm{H}-3^{\mathrm{IV}}, \mathrm{OCH}\right), 3.37-3.33(\mathrm{~m}, 3 \mathrm{H}$,
$\left.\mathrm{H}-4^{\mathrm{II}}, \mathrm{H}-5^{\mathrm{IV}}, \mathrm{OCH}\right), 2.20,2.12,2.10,2.03,1.85(5 \mathrm{~s}$, $\left.5 \times 3 \mathrm{H}, 5 \mathrm{CH}_{3} \mathrm{CO}\right), 1.56,1.42,1.34,1.19(4 \mathrm{~s}, 4 \times 3 \mathrm{H}$, $\left.2\left(\mathrm{CH}_{3}\right)_{2} \mathrm{C}\right), 1.61-1.57\left(\mathrm{~m}, 2 \mathrm{H}, \mathrm{OCH}_{2} \mathrm{CH}_{2}\right), 1.30-1.27$ $\left(\mathrm{m}, 10 \mathrm{H}, 5 \mathrm{CH}_{2}\right), 1.20\left(\mathrm{~d}, 6 \mathrm{H}, J 6.3 \mathrm{~Hz}, \mathrm{H}-6^{\mathrm{I}}, \mathrm{H}-6^{\mathrm{III}}\right)$, $1.14\left(\mathrm{~d}, 3 \mathrm{H}, J 6.3 \mathrm{~Hz}, \mathrm{H}-6^{\mathrm{II}}\right), 0.89(\mathrm{t}, 3 \mathrm{H}, J 7.0 \mathrm{~Hz}$, $\left.\mathrm{CH}_{3}\right) .{ }^{13} \mathrm{C}$ NMR $\left(100 \mathrm{MHz}, \mathrm{CDCl}_{3}\right): \delta 170.7,170.4$, $170.2,170.1,169.5,138.3,138.1,137.8,137.4,134.2$, $129.0,128.4,128.3,128.2,128.1,128.0,127.9,127.8$, $127.7,127.6,127.5,127.4,109.3,109.0,100.0,97.6$, $97.4,96.8,95.4,79.8,78.5,78.0,77.5,77.3,77.0,76.7$, 75.8, 75.1, 74.6, 74.0, 73.6, 73.1, 71.4, 71.3, 70.6, 69.1, $69.0,67.8,67.6,67.3,64.5,63.8,61.6,54.8,31.8,29.3$, $29.2,29.1,27.9,27.8,26.3,26.1,22.6,21.4,21.2,21.0$, 20.7, 20.6, 20.6, 18.0, 17.7, 17.6, 14.0. MALDITOFMS: calcd for $\mathrm{C}_{83} \mathrm{H}_{107} \mathrm{NO}_{29}, \mathrm{~m} / \mathrm{z} 1581$; found: $\mathrm{m} / \mathrm{z}$ $1604.8(\mathrm{M}+\mathrm{Na})^{+}, 1620.8(\mathrm{M}+\mathrm{K})^{+}$. Anal. Calcd for $\mathrm{C}_{83^{-}}$ $\mathrm{H}_{107} \mathrm{NO}_{29}$ : C, 62.99; H, 7.81. Found: C, 63.28; H, 7.72.

\subsection{Octyl 2-acetamido-2-deoxy- $\beta$-D-glucopyranosyl-} $(1 \rightarrow 4)$-[ $\beta$-D-mannopyranosyl- $(1 \rightarrow 2)]-\alpha$-L-rhamnopyranoyl-( $1 \rightarrow 4)-\alpha-L-r h a m n o p y r a n o s y l-(1 \rightarrow 4)-\alpha-L-$ rhamnopyranoside (1)

Compound 19 (410 mg, $0.26 \mathrm{mmol}$ ) was dissolved in 90\% aq acetic acid $(8 \mathrm{~mL})$ and stirred under reflux for $30 \mathrm{~min}$. At the end of this time, TLC indicated all starting material was consumed. The mixture was co-evaporated with toluene under diminished pressure to give a syrup, which was subjected to hydrogenation with $\mathrm{H}_{2}$ under a flow rate of $100 \mathrm{~mL} / \mathrm{min}$ in the presence of $20 \% \mathrm{Pd}(\mathrm{OH})_{2}$ on charcoal $(209 \mathrm{mg}, 0.14 \mathrm{mmol})$ in $1: 1 \mathrm{MeOH}-\mathrm{EtOAc}$ $(20 \mathrm{~mL})$ for $70 \mathrm{~h}$. The reaction mixture was filtered, the filtrate was concentrated, and the syrup was treated with $\mathrm{Ac}_{2} \mathrm{O}(2 \mathrm{~mL})$ in pyridine $(4 \mathrm{~mL})$ for $4 \mathrm{~h}$ at $\mathrm{rt}$. After co-evaporation with toluene, the residue (about $320 \mathrm{mg}$ ) was dissolved into $\mathrm{NH}_{3}$-saturated 4:1 $\mathrm{MeOH}-\mathrm{CH}_{2} \mathrm{Cl}_{2}$ $(50 \mathrm{~mL})$ and stirred at $\mathrm{rt}$ for 6 days, then concentrated under diminished pressure. The residue was dissolved in $\mathrm{H}_{2} \mathrm{O}(1 \mathrm{~mL})$ and passed through a Sephadex LH-20 column with $\mathrm{H}_{2} \mathrm{O}$ as eluent yielding foamy intermediate (about $175 \mathrm{mg}$ ) after freeze drying. Acetylation of this intermediate as described in the preparation of $\mathbf{1 4}$, followed by purification on a silica gel column (3:2 petroleum ether-EtOAc) gave an amorphous solid. To a solution of the above solid in $\mathrm{MeOH}$ was added $\mathrm{NaOMe}$ (1.0 M, kept at $\mathrm{pH} 9-10)$ at rt. The reaction mixture was stirred for $3 \mathrm{~h}$, then neutralized with Amberlite IR-120 $\left(\mathrm{H}^{+}\right)$, and filtered. The filtrate was concentrated, and the residue was purified on a Sephadex LH-20 column with $\mathrm{H}_{2} \mathrm{O}$ as eluent to finish compound $1(143 \mathrm{mg}, 59 \%$ from 19) as a white foam after freeze drying: $[\alpha]_{\mathrm{D}}^{25}-32$ (c 1, $\mathrm{H}_{2} \mathrm{O}$ ); Selected ${ }^{1} \mathrm{H}$ NMR $\left(400 \mathrm{MHz}, \mathrm{CD}_{3} \mathrm{OD}\right) \delta$ $5.46\left(\mathrm{~d}, 1 \mathrm{H}, J 1.2 \mathrm{~Hz}, \mathrm{H}-1^{\mathrm{II}}\right), 5.14(\mathrm{~d}, 1 \mathrm{H}, J 1.6 \mathrm{~Hz}, \mathrm{H}-$ $\left.1^{\mathrm{III}}\right), 4.76\left(\mathrm{~d}, 1 \mathrm{H}, J 8.3 \mathrm{~Hz}, \mathrm{H}-1^{\mathrm{V}}\right), 4.62$ (br s, $2 \mathrm{H}, \mathrm{H}-1^{\mathrm{I}}$, $\left.\mathrm{H}-1^{\mathrm{IV}}\right), 4.03\left(\mathrm{dd}, 1 \mathrm{H}, J 1.6,3.4 \mathrm{~Hz}, \mathrm{H}-2^{\mathrm{III}}\right), 4.01(\mathrm{~d}, 1 \mathrm{H}$,

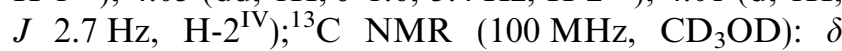


$174.4,103.7,103.3,102.9,102.3,101.4,81.7,81.3,81.2$, $80.9,78.7,77.8,76.7,75.2,73.3,73.2,72.9,72.7,72.2$, $72.0,68.8,68.5,68.2,63.1,62.9,58.2,33.0,30.5,30.4$, 27.3, 23.7, 23.0, 18.7, 18.4, 18.1, 14.5. MALDITOFMS: calcd for $\mathrm{C}_{40} \mathrm{H}_{71} \mathrm{NO}_{23}, \mathrm{~m} / z$ 933; found: $\mathrm{m} / \mathrm{z}$ 956.1 $(\mathrm{M}+\mathrm{Na})^{+}, 972.1(\mathrm{M}+\mathrm{K})^{+}$. Anal. Calcd for $\mathrm{C}_{40} \mathrm{H}_{71^{-}}$ $\mathrm{NO}_{23}$ : C, 51.44; H, 7.66. Found: C, 51.19; H, 7.79.

\subsection{Bioassays of compound 1}

M1 cells $\left(3 \times 10^{5} /\right.$ well $)$ were cultured in a suspension of Dulbcco's Modified Eagle Medium (DMEM) supplemented with $10 \%$ newborn calf serum in a humidified atmosphere at $37{ }^{\circ} \mathrm{C}$ containing $5 \% \mathrm{CO}_{2}$. Compound $\mathbf{1}$ was applied at concentrations of 10,20 , and $50 \mu \mathrm{g} / \mathrm{mL}$ according to the dosage applied for natural latosillan in the literature, ${ }^{4}$ while positive control all-trans-retinoic acid (ATRA) was used at $1 \mu \mathrm{mol} / \mathrm{L}$. DMEM medium was used as a negative control. At the end of 3 days of incubation, the cells were harvested by centrifugation, and then suspended in nitroblue tetrazolium (NBT) solution $(100 \mu \mathrm{L}, 4.0 \mathrm{mg} / \mathrm{mL})$, and $12-O$-tetradecanoylphorbol-13-acetate (TPA, $100 \mu \mathrm{L}, 2.0 \mu \mathrm{g} / \mathrm{mL}$ ) was added. The cell suspension was incubated at $37^{\circ} \mathrm{C}$ for $20 \mathrm{~min}$, and $1 \mathrm{~N} \mathrm{HCl}(200 \mu \mathrm{L})$ was added at $4{ }^{\circ} \mathrm{C}$ to terminate the reaction. After centrifugation, DMSO $(600 \mu \mathrm{L})$ was added to the cell pellets, and the amount of formazan formed in this process was measured at $560 \mathrm{~nm}$ with a microplate reader.

\section{Acknowledgments}

This work was supported by NNSF of China (Projects 20372081, 30330690).

\section{References}

1. Ichikawa, Y. J. Cell. Physiol. 1969, 74, 223-234.

2. Sachs, L. Nature 1978, 274, 535-539.

3. Abe, E.; Miyaura, C.; Sakagami, H.; Konno, K.; Yamazaki, T.; Yoshiki, S.; Suda, T. Proc. Natl. Acad. Sci. U.S.A. 1981, 78, 4990-4994.

4. Hayakawa, Y.; Ando, T.; Shimazu, A.; Seto, H.; Otake, N. Agric. Biol. Chem. 1985, 49, 2437-2442.

5. (a) Hayakawa, Y.; Nakagawa, M.; Ando, T.; Shimazu, A.; Seto, A.; Otake, N. J. Antibiot. 1982, 35, 1252-1254; (b) Hayakawa, Y.; Nakagawa, M.; Seto, A.; Otake, N. Agric. Biol. Chem. 1985, 49, 2443-2446.

6. (a) Yu, B.; Yu, H.; Hui, Y.; Han, X. Tetrahedron Lett. 1999, 40, 8591-8594; (b) van Steijn, A. M. P.; Jetten, M.; Kamerling, J. P.; Vliegenthart, J. F. G. Recl. Trav. Chim. Pays-Bas 1989, 108, 374-383.

7. (a) Zemplén, G.; Kunz, A. Ber. Dtsch. Chem. Ges. 1923, 56B, 1705-1710; (b) Du, Y.; Pan, Q.; Kong, F. Carbohydr. Res. 2000, 329, 17-24.

8. (a) Reimer, K. B.; Harris, S. L.; Varma, V.; Pinto, B. M. Carbohydr. Res. 1992, 228, 399-414; (b) Marino-Albernas, J.-R.; Harris, S. L.; Varma, V.; Pinto, B. M. Carbohydr. Res. 1993, 245, 245-257.

9. (a) Chou, C.-H.; Wu, C.-S.; Chen, C.-H.; Lu, L.-D.; Kulkarni, S. S.; Wong, C.-H.; Hung, S.-C. Org. Lett. 2004, 6, 585-588; (b) Maloney, D. J.; Hecht, S. M. Org. Lett. 2005, 7, 1097-1099.

10. Du, Y.; Wei, G.; Linhardt, R. J. J. Org. Chem. 2004, 69, 2206-2209.

11. Pfitzner, K. E.; Moffatt, J. G. J. Am. Chem. Soc. 1965, 87, 5661-5670.

12. (a) Liu, K. K. C.; Danishefsky, S. J. Org. Chem. 1994, 59, 1892-1894; (b) Warren, C. D.; Augé, C.; Laver, M. L.; Suzuki, S.; Power, D.; Jeanloz, R. W. Carbohydr. Res. 1980, 82, 71-81; (c) Crich, D.; Sun, S. Tetrahedron Lett. 1998, 39, 1681-1684.

13. Du, Y.; Zhang, M.; Kong, F. Tetrahedron 2001, 57, 17571763.

14. Kohroki, J.; Muto, N.; Tanaka, T.; Itoh, N.; Inada, A.; Tanaka, K. Leukemia Res. 1998, 22, 405-412. 